\title{
From Our Historical Collection: The King's Speech
}

\section{Simon Moorhead}

Ericsson

Summary: A seemingly dry, technical paper from 1937 in the Telecommunications Journal of Australia offers much broader interest following the popularity of the 2010 film 'The King's Speech'. The June 1937 paper by A.H. Kaye describes the engineering networking arrangements set up by the Australian Postmaster General's Department to transmit across Australia the BBC's audio commentary on King George VI's coronation to all Australian national and commercial radio stations. The six hour broadcast included the now famous speech by the newly crowned King to his British Commonwealth.

\section{Introduction to the historical paper}

Today, international telecommunications and Internet broadcasting, to and from Australia, are taken for granted. Not so long ago, overseas broadcasts to Australia were bound by the vagaries of HF propagation.

Our historical paper for this issue (Kaye 1937) is taken from Volume 1, Number 5 of the Telecommunications Journal of Australia (TJA), dated June 1937. It describes the extensive telecommunications engineering required to bring the King George VI coronation broadcast to Australians, on 12 May 1937.

This apparently dry and technical paper is fascinating today seen through fresh eyes, given the popularity of the film 'The King's Speech', starring Geoffrey Rush and Colin Firth (Wikipedia 2014).

The TJA paper was written by A H Kaye, who went on to present the Australian Faraday lecture in 1972. Mr Kaye also produced a booklet for the Postmaster-General's Department (PMG) entitled 'Telecommunications in Australia: a short history of telecommunications', based on his Faraday lecture.

The 1937 paper provides a brief introduction to High Frequency (HF) propagation, which may not be well known to our younger readers. It discusses the challenges of a 9 a.m. (Greenwich Mean Time) broadcast in the United Kingdom being received by HF stations in Australia, given the ionosphere does not reflect HF signals unless bathed in sunlight. 
The PMG engineers determined that the broadcast could be relayed by several powerful stations re-transmitting from Hong Kong and North America, provided they selected the optimal propagation frequencies and utilised diversity reception in Australia to compensate for HF propagation fading.

There was close co-operation between the PMG, representing the National Broadcasters, and AWA Ltd. representing the Commercial Broadcasters, to re-transmit the coronation broadcast within Australia.

Several interstate HF receiving stations provided diversity reception and the paper details how the programme feeds were switchable between receiving stations to compensate for signal fading. An elaborate configuration of relay feeds was also provided to 96 broadcast stations via the National Broadcasting network and via AWA Ltd to the Commercial Broadcasters.

One historic limitation was the single telephone circuit between South Australia and Western Australia, which was not available for the broadcast. The commercial broadcasters were therefore forced to establish alternate receiving stations in WA for an East-West link.

Through the work of the personnel involved, the relay held up throughout the King's Speech and for five hours of related broadcasts. This was considered very lucky given recent sunspot activity had all but ruined HF propagation the day before. 


\section{The historical paper}

\section{BROADCAST IN AUSTRALIA OF THE BRITISH BRoAdGASTING GORPORATION GORONATION PROgRAMME.}

A. H. Kaye, B.Sc.

Brief Description of Short Wave Propagation. - It is generally well known that the reception of "short" radio waves over long distances depends on the presence about 150 miles above earth of a "layer" of ionized atmosphere. The frequencies in question cover the range approximately 6 to 20 megacycles per second or wave lengths 50 to 15 metres. This layer, is, in fact, much more complicated than a simple envelope around the earth, but this need noit concern us here.

The rays transmitted straight along the ground are of little use for the purpose discussed, but a ray projected skywards is refracted or bent as it passes through the ionized layer, this bending in the useful cases continuing until the ray is re-directed towards the earth. Further "reflections" between earth and layer carry the signal around the globe. For" any particular ionic density there is a maximum usable frequency, above which the bending is insufficient and all rays penetrate the layer and are lost; and in general the attenuation goes up with decreasing frequency. This ionic density increases with the intensity of sunlight and, as the great circle, i.e. the direct route, between two points a long way apart on the earth's surface, of necessity passes through varying intensities, the selection of usable frequencies must first ensure that we are below penetration frequency over the whole path and that the attenuation is not so great that the signal is lost in atmospheric noise, etc. These requirements are often incompatible, and communication on short waves is then impracticable.

Due largely to the work of Eckersley and Tremellin, data has been prepared from which it is possible, by consideration of the distribu-

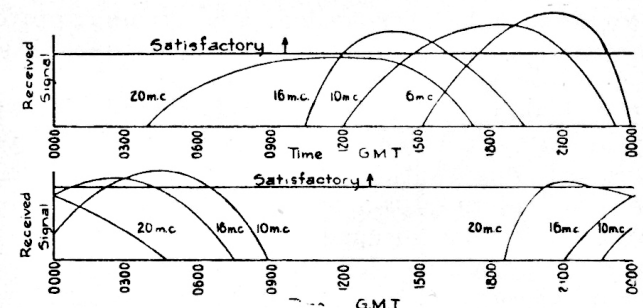

Fig. 1.- Propagation conditions between London and Melbourne during May. Top figure shows the received signal path, and bottom figure over the longer great circle path.

tion over the earth's surface of sunlight in its various degrees from strong summer sunlight to darkness at a given time and season, to fore- cast the received signals and hence select the most suitable frequency; but of course extraneous effects such as local storms, sun spot disturbances, etc., may, even so, spoil transmission. Curves showing the signal strength to be expected in Melbourne of a London transmission, assuming a $10 \mathrm{kw}$. transmitter and a simple receiver, are shown in Figure 1 . These curves are merely relative, but for average weather conditions are quite reliable.

The British Broadcasting Corporation Coronation Broadcasts.-Proceeding to the subject proper of this article, namely, the arrangements made for receiving the broadcast descriptions of the Coronation of His Majesty King George VI, emanating from the B.B.C. transmitters at Daventry, the time of the ceremony, 7 p.m. to 12.30 a.m. E.S.T. (0900 to 1430 G.M.T.) covered a period, say up to 10 p.m., during which reception from England was practically impossible for the reasons discussed above-(See Figure 1). After the description of the Coronation proper, further items were required, but as these were either at a good time or were merely repetitions we need not consider them further.

Consideration was, therefore, given to receiving a relay via another country. Examination of sunlight conditions, supplemented by observations, showed that reception was most likely through Hong Kong, Northern America or the Dutch Indies, and enquiry revealed that each of these countries possessed high power transmitters rebroadcasting at least portions of the required programme. A good deal of hope was placed in Hong Kong, as calculations showed transmission from London to Hong Kong on about 16 megacycles to be excellent, whilst 10 megacycles was very good Hong Kong to Melbourne, although neither frequency was suitable London to Me!bourne.

This arrangement proved most helpful, and for the actual programme 116 minutes' transmission was taken through Hong Kong, 74 minutes from Canada, 33 minutes from U.S.A. and 157 minutes direct from London.

Receiving Arrangements.-In order to have thorough search for the best programme, and to avoid trouble due to local static and interference, the resources of the PostmasterGeneral's Department and Amalgamated Wirelcss (A'sia) Ltd. were pooled. Eight receiving stations distributed over a wide area were brought into use, each station searching with a number of receivers and supplying the best programme found, whether direct from Daventry or from rebroadcasting stations, to a Special 
Central Control Room set up in the City West Exchange Building, Melbourne, where representatives of the Post Office and the Australian Broadcasting Commission selected the best transmission for use over the National network. This arrangement is shown in Figure 2.

All the equipment in the Special Control Room, being the nerve centre of the organisation, was in duplicate, and order wires were held for speaking and for emergency use to each main point, as Melbourne Test Room, 3LO Control Room, Recorder Room, etc. The programme

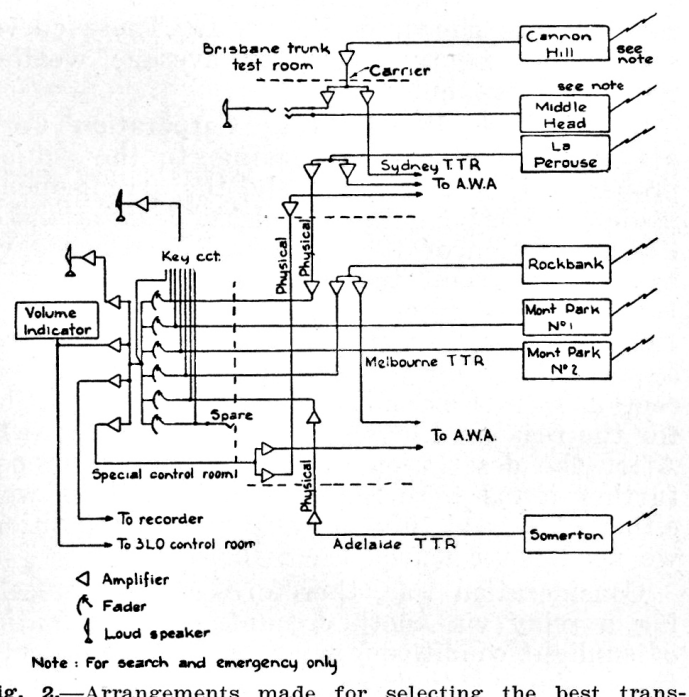

Fig. 2--Arrangements made for selecting the best trans-
mission from those provided by receiving
stations.

selected by each receiving station was monitored from time to time at this point, and the best available transmitted to $3 \mathrm{LO}$ for relay in the ordinary way.

This selection was also provided to the offices of A.W.A. for use if required by the Commercial station networks. It is interesting to note that at times it was found possible to reduce fading and improve quality by mixing the programme from Mont Park and La Perouse, these two receiving stations having selected the same transmitter. In all, 20 changes were made in the receiving station selected by the Special Control Room.

The Relay Network.-In order to provide for relaying the National programme from $3 \mathrm{LO}$ Melbourne to all National stations, from the Melbourne offices of A.W.A. to Victorian, South Australian and Tasmanian Commercial stations, and from the Sydney offices of A.W.A. to New South Wales and Queensland Commercial stations, approximately 16,000 miles of land line was required, apart from those circuits used by the Trunk Test Roomsi Staffs for lining up. In nearly all cases carrier programme systems or physical lines were available, thus providing, after replacing the usual telephone repeaters, etc. by special programme amplifying equipment, "music" circuits transmitting an audio frequency band of approximately 50 to 5,000 cycles per second.

Figure 3 indicates the arrangement of the equipment required for this purpose as set up in the Melbourne Trunk Test Room.

West Australian Arrangements.-A difficulty was struck in connection with the provision of a programme for the Commercial stations in Western Australia as, to provide a line from Adelaide, would take the only telephone circuit available. For this reason a local receiving centre was set up using four short-wave receivers in and near Perth, from which centre programme was provided with satisfactory results. The change of receiving signal with location wasi clearly demonstrated here, for the locally received programme was considerably better than that received over the National pro-

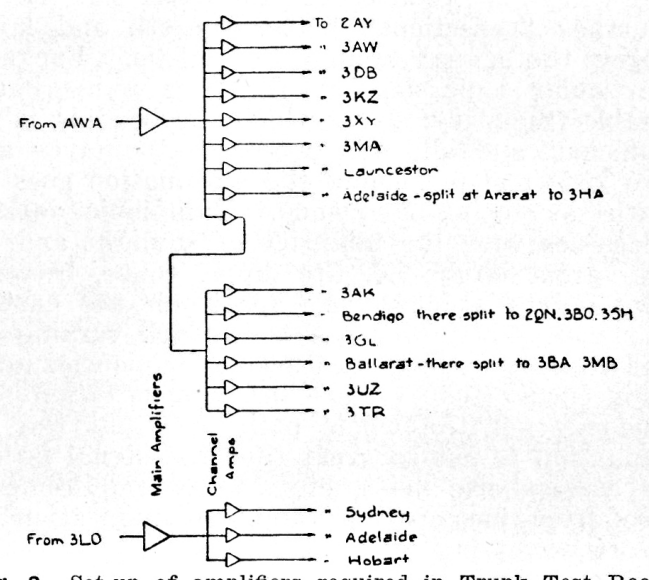

Fig. 3.- Set-up of amplifiers required in Trunk Test Room, mercial stations.

gramme line from the Eastern States at the beginning but later failed, and from approximately 10 p.m. onwards reception in the Eastern States was superior.

Conclusion.-It might be mentioned that reception of short waves on previous nights was very bad, due to the presence of sun-spots, and the Australian Broadcasting Commission had prepared for use in case of emergency an appropriate programme for production in the Melbourne studios. This was not used at any time owing to the satisfactory reception of rebroadcasting stations, and from the point of view of the listening public the programme was apparently satisfactory-adequate justification for the somewhat elaborate precautions. In all, a total of 96 National and Commercial stations participated in the programme. 


\section{Enlargement of the Figures}
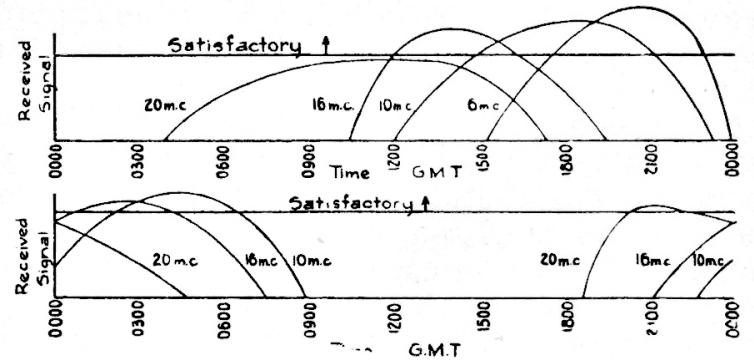

Fig. 1.-Propagation conditions between London and Melbourne during May. Top figure shows the received signal path, and bottom figure over the longer great circle path.
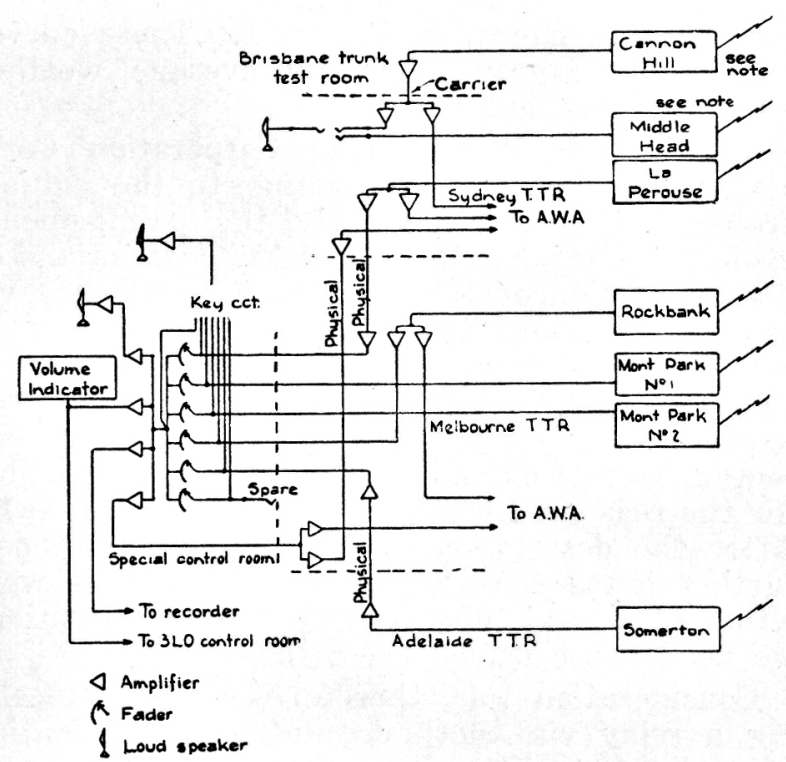

1 Loud speaker

Note : for search and emergency only

Fig. 2.-Arrangements made for selecting the best transmission from those provided by receiving stations.

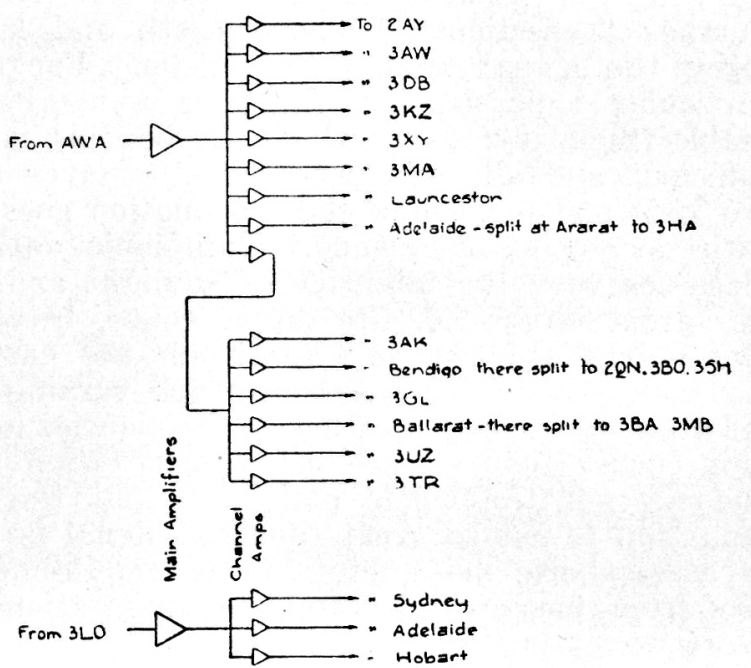

Fig. 3.-Set-up of amplifiers required in Trunk Test Room Melbourne, for relay of programme to National and Commercial stations. 


\section{References}

Kaye, A.H. 1937. 'Broadcast in Australia of the British Broadcasting Corporation Coronation Programme', Telecommunications Journal of Australia, June 1937, Vol. 1, No. 5, pp. 227228.

Wikipedia. 2014. 'The King's Speech', at https://en.wikipedia.org/wiki/The King's Speech

\section{Cite this article as:}

Simon Moorhead. 2014. From Our Historical Collection: The King's Speech. Australian Journal of Telecommunications and the Digital Economy, Vol 2, No 2, Article 36.http://doi.org/10.7790/ajtde.v2n2.36.

Published by Telecommunications Association Inc. ABN 34732327 053. http://telsoc.org 